\title{
Figures and boxes
}

\section{FIGURES}

2.1 A prescriptive analysis of search and discovery 26

4.1 Predicted venture performance vs. actual venture performance 93

7.1 Model of discovery and firm founding 148

8.1 A framework for determining the attributes of a forgiving business model

\section{BOXES}

3.1 Standards for conclusions derived from qualitative studies 73

4.1 Entrepreneurial fit - criteria and contingency rules $\quad 80$

4.2 Value - criteria and contingency rules $\quad 82$

Panel A: Potential entrants

Panel B: Rivalry

Panel C: Suppliers

Panel D: Buyers

Panel E: Substitutes

$\begin{array}{lll}4.3 & \text { Rarity - criteria and contingency rules } & 87\end{array}$

4.4 Inimitability - criteria and contingency rules 88

4.5 Kappa and its calculation 95 